\title{
Effect of increasing the fat content but not the energy load of a meal on gastro-oesophageal reflux and lower oesophageal sphincter motor function
}

\author{
R Penagini, M Mangano, P A Bianchi
}

\begin{abstract}
Background-Although fatty foods are commonly considered detrimental in patients with reflux disease, no objective data exist that substantiate this belief.

Aims-To investigate the effect of fat on gastro-oesophageal reflux and lower oesophageal sphincter (LOS) motor activity.
\end{abstract}

Subjects-Thirteen healthy subjects and 14 patients with reflux disease.

Methods-Oesophageal pH, LOS, and oesophageal pressures were recorded for 180 minutes after a high fat (52\% fat) and a balanced ( $24 \%$ fat) meal (both $3.18 \mathrm{MJ}$ ) on two different occasions. Eight controls and seven patients were studied in the recumbent position and the others in the sitting position.

Results-The percentage of time at $\mathbf{p H}$ less than 4 and the rate of reflux episodes were higher $(p<0.01)$ in the patients than in the healthy subjects (mean $14.1 \%$ versus $1.7 \%$ and $4.4 / \mathrm{h}$ versus $0.8 / \mathrm{h}$ respectively), as was the percentage of transient LOS relaxations associated with reflux $(62 \%$ versus $32 \%, p<0.01)$. The high fat meal did not increase the rate of reflux episodes nor exposure to oesophageal acid in either group regardless of body posture. The rate of transient LOS relaxations, their association with reflux, and basal LOS pressure were also unaffected.

Conclusions-Increasing fat intake does not affect gastro-oesophageal reflux or oesophagogastric competence for at least three hours after a meal.

(Gut 1998;42:330-333)

Keywords: oesophagus; oesophagogastric junction; gastro-oesophageal reflux; fat

Cattedra di

Gastroenterologia,

Istituto di Scienze

Mediche, University of

Milan-IRCCS

Ospedale Maggiore,

Milan, Italy

R Penagini

M Mangano

P A Bianchi

Correspondence to:

Dr R Penagini, IRCCS

Ospedale Maggiore, Pad

Granelli, Via F Sforza 35,

20122 Milan, Italy.

Accepted for publication

23 September 1997
Fatty foods are often reported by patients with gastro-oesophageal reflux disease to precipitate heartburn ${ }^{1}$ and it is a common belief among physicians that they are contraindicated in these patients. However, there are no data that substantiate these notions. ${ }^{2}$

The aim of the study was to evaluate the effect of a high fat meal compared with an equal energy balanced meal on gastrooesophageal reflux and on the main variables of lower oesophageal sphincter (LOS) competence - that is, transient LOS relaxation and basal LOS pressure, ${ }^{34}$ using combined oesophageal $\mathrm{pH}$ and pressure monitoring.
Methods

STUDY GROUP

Thirteen healthy subjects (aged 19-38 years; eight men) and 14 patients with gastrooesophageal reflux disease (aged 23-60 years; 10 men) were enrolled in the study which was approved by the Human Research Review Committee of the Maggiore Hospital, Milan. The healthy subjects had no symptoms or past history of gastrointestinal disease and the patients had either abnormal 24 hour intraoesophageal $\mathrm{pH}$ monitoring (more than 5\% of time at $\mathrm{pH}$ less than 4$)(\mathrm{n}=8)$ or erosive oesophagitis $(n=6)$.

MANOMETRIC AND $\mathrm{pH}$ RECORDING TECHNIQUE Oesophageal motility was monitored using an assembly of polyvinyl tubes incorporating a sleeve sensor (Dentsleeve, Belair, Australia). The $6 \mathrm{~cm}$ long sleeve was positioned so that it straddled the LOS. A side hole $1 \mathrm{~cm}$ below the distal margin of the sleeve recorded intragastric pressure. Side holes at the upper margin of the sleeve and 5 and $10 \mathrm{~cm}$ more proximally monitored motor activity of the oesophageal body 2 , 7 , and $12 \mathrm{~cm}$ above the LOS. One of two side holes 23 and $28 \mathrm{~cm}$ proximal to the upper margin of the sleeve monitored swallows in the pharynx. Each lumen was connected to a pressure transducer (model 4-327-I, Sensormedics, Anaheim, USA) and perfused with distilled water by a low compliance pneumohydraulic infusion pump (Arndorfer, Greendale, Wisconsin, USA; response: $>200 \mathrm{~mm} \mathrm{Hg} / \mathrm{s}$ at 0.5 $\mathrm{ml} / \mathrm{min}$ ). The gastric side hole and sleeve were perfused at $0.5 \mathrm{ml} / \mathrm{min}$, whereas the side holes in the oesophageal body and in the pharynx were perfused at $0.13 \mathrm{ml} / \mathrm{min}$ in order to minimise the fluid load to the subject. Intraoesophageal $\mathrm{pH}$ was monitored using a bipolar intraluminal $\mathrm{pH}$ electrode (Ingold 440M4, Urdorf, Switzerland) positioned $5 \mathrm{~cm}$ above the proximal margin of the LOS. Signals from the pressure transducers and $\mathrm{pH}$ electrode were processed and recorded on a polygraph (model R711, Sensormedics, Anaheim, USA) at a paper speed of $2.5 \mathrm{~mm} / \mathrm{s}$.

EXPERIMENTS

All subjects were studied on two different occasions, in randomised order, at least two days apart. After an overnight fast the subjects swallowed the assembly. When they felt comfortable, the study started with administration of the test meal. On both occasions the subjects ate one sandwich and drank $150 \mathrm{ml}$ of a commercially available diet formula (Ensure, Abbott, Italy); $450 \mathrm{ml}$ of a high fat or balanced 
Table 1 Composition of the two meals

\begin{tabular}{lll}
\hline & Balanced meal & High fat meal \\
\hline Lipids & $20 \mathrm{~g}(24 \%)$ & $44 \mathrm{~g} \mathrm{(52 \% )}$ \\
Carbohydrates & $114 \mathrm{~g}(60 \%)$ & $74 \mathrm{~g} \mathrm{(39 \% )}$ \\
Proteins & $29 \mathrm{~g} \mathrm{(16 \% )}$ & $17 \mathrm{~g} \mathrm{(9 \% )}$ \\
MJ & 3.16 & 3.18 \\
\hline
\end{tabular}

Percentage of total energy content of the meal in brackets.

solution, with an osmolarity of $350 \mathrm{mOsm} / 1$ in each case, was infused directly into the stomach at a speed of $40 \mathrm{ml} / \mathrm{min}$ through the core of the manometric assembly. The balanced solution consisted of $450 \mathrm{ml}$ of Ensure; the high fat solution consisted of $150 \mathrm{ml}$ of Ensure, $150 \mathrm{ml}$ of a lipid emulsion (Lipofundin S $20 \%$, Braun, Italy), and $150 \mathrm{ml}$ of saline solution. Table 1 summarises the composition of the two meals.

After the end of the infusion oesophageal motility and $\mathrm{pH}$ were recorded for 180 minutes. Eight healthy subjects and seven patients were studied in the recumbent position, and five healthy subjects and seven patients in the sitting position. Controls and patients were not allowed to sleep.

ANALYSIS OF RECORDS

Oesophageal acid exposure was expressed as percentage of time at $\mathrm{pH}$ less than 4 . A reflux episode was defined as either a $\mathrm{pH}$ drop to less than 4 for at least four seconds or, if basal oesophageal $\mathrm{pH}$ was already below 4 , a further abrupt drop of more than $1 \mathrm{pH}$ unit. Transient LOS relaxation was defined as already described, ${ }^{5}$ and reflux was judged to have accompanied a transient LOS relaxation if an abrupt fall in oesophageal $\mathrm{pH}$ of more than 1 $\mathrm{pH}$ unit occurred during the relaxation. End expiratory basal LOS pressure, referenced to end expiratory intragastric pressure, was calculated as the mean of the average pressure of one minute every five minutes. Analysis of transient LOS relaxation could not be performed in five patients because LOS pressure was too low (less than $3 \mathrm{~mm} \mathrm{Hg}$ ) for most of the recording period to allow assessment.

\section{STATISTICAL ANALYSIS}

Data are expressed as mean (SEM). The statistical significance of differences between the high fat and the balanced meal and between healthy subjects and patients was evaluated using paired and unpaired Student's $t$ test, respectively.

Table 2 Gastro-oesophageal reflux variables according to body posture

\begin{tabular}{lll}
\hline & Balanced meal & High fat meal \\
\hline Time at $p H<4(\%)$ & & \\
Recumbent controls & $2.6(0.9)$ & $2.5(1.8)$ \\
Sitting controls & $0.1(0.1)$ & $0.1(0.1)$ \\
Recumbent patients & $19.5(6.5)$ & $16.5(7.5)$ \\
Sitting patients & $8.6(2.9)$ & $6.3(2.4)$ \\
Rate of reflux episodes (no/h) & & \\
Recumbent controls & $1.0(0.4)$ & $1.1(0.7)$ \\
Sitting controls & $0.4(0.2)$ & $0.6(0.4)$ \\
Recumbent patients & $4.8(1.7)$ & $5.2(1.9)$ \\
Sitting patients & $3.9(1.1)$ & $2.4(0.7)$ \\
\hline
\end{tabular}

Data are expressed as mean (SEM).

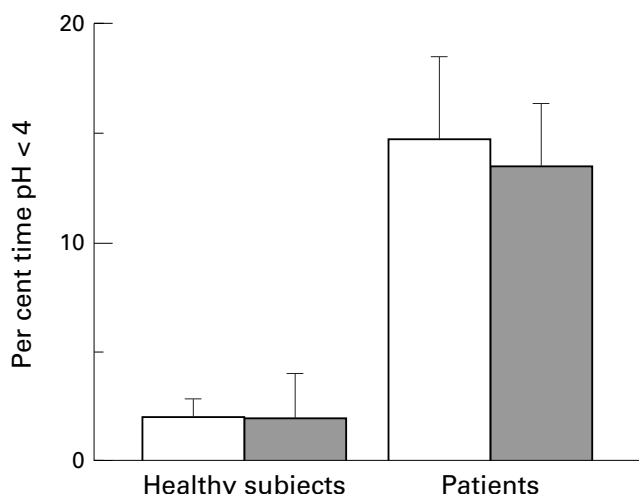

Figure 1 Oesophageal acid exposure after the balanced (open column) and the high fat meals (shaded column). Data are expressed as mean (SEM).

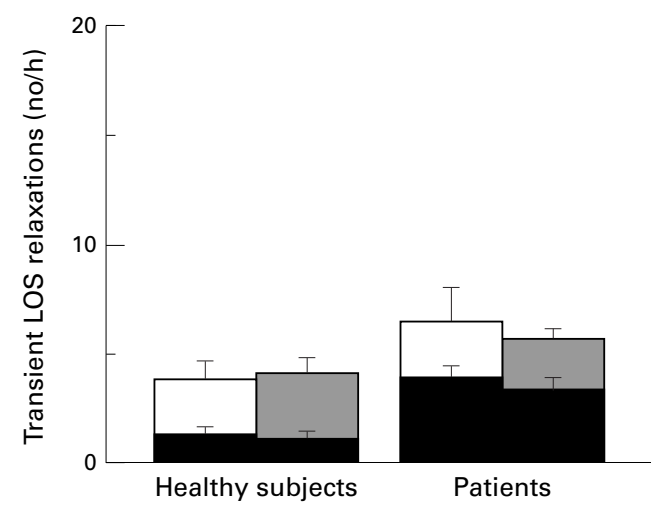

Figure 2 Rate of transient LOS relaxations and proportion associated with reflux, shown in black, after the balanced (open column) and the high fat meals (shaded column). Data are expressed as mean (SEM).

\section{Results}

GASTRO-OESOPHAGEAL REFLUX

After the balanced meal the patients had a higher oesophageal acid exposure and rate of reflux episodes $(p<0.01)$ than the healthy subjects $(14.1(3.7) \%$ versus $1.7(0.6) \%$ and 4.4 $(0.9) / \mathrm{h}$ versus $0.8(0.2) / \mathrm{h}$; fig 1$)$. The high fat meal did not affect these variables in either group, regardless of body posture (table 2 and fig 1). No difference in response to the high fat meal was found between the five patients showing absent (less than $3 \mathrm{~mm} \mathrm{Hg}$ ) LOS pressure for most of the recording time after the balanced meal and the remainder of the study population.

TRANSIENT LOS RELAXATION

After the balanced meal the rate of transient LOS relaxations showed a trend towards higher values in the patients compared with the healthy subjects $(6.4(1.6) / \mathrm{h}$ versus $3.5(0.5) / \mathrm{h}$; $\mathrm{p}=0.1$ ), and the percentage of these events associated with reflux was higher in the patients (62 (7) \% versus $32(8) \%$; $<<0.01$; fig 2 ). The high fat meal did not affect the rate of transient LOS relaxations or their association with reflux in either group (fig 2).

BASAL LOS PRESSURE

Overall basal LOS pressure did not differ in the patients compared with the healthy subjects after the balanced meal (7 (2) $\mathrm{mm} \mathrm{Hg}$ versus 11 (2) $\mathrm{mm} \mathrm{Hg}$; fig 3). However, whereas all 


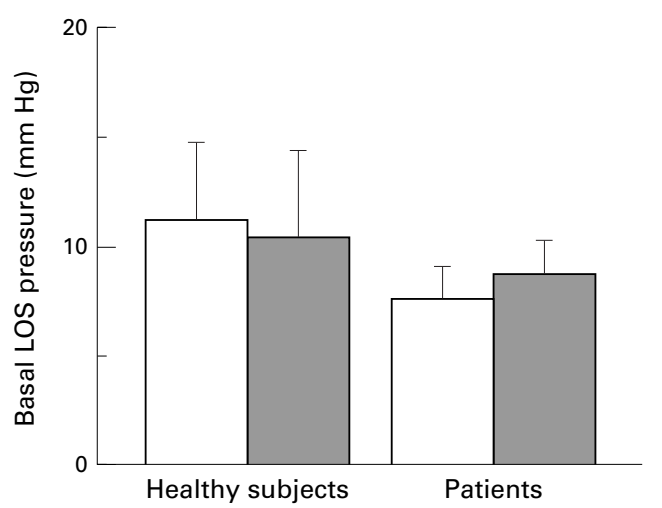

Figure 3 Basal LOS pressure after the balanced (open column) and the high fat meals (shaded column). Data are expressed as mean (SEM).

healthy subjects always had a pressure of greater than $3 \mathrm{~mm} \mathrm{Hg}$, basal LOS pressure was almost undetectable during the whole observation period in two patients and during the first 90 minutes in three others. Basal LOS pressure was unaffected by the high fat meal in either group (fig 3).

\section{Discussion}

In the present study a high fat meal did not promote gastro-oesophageal reflux or alter LOS motor function in either healthy subjects or patients with reflux disease, when compared with an equal energy balanced meal. This seems surprising in light of the currently held belief that fat worsens gastro-oesophageal reflux, but is in line with the few reports in the literature. The only previous study to look at the effect of a high fat compared with a low fat meal on oesophageal acid exposure over three postprandial hours in both the recumbent and upright posture ${ }^{2}$ showed no difference in the patients with reflux disease and an increase after the high fat meal in the healthy subjects, in the upright posture only. However, whether the latter result depended on an increase in the rate of reflux episodes or not is unclear as this rate was not presented. A recent experimental study ${ }^{6}$ showed that, compared with saline infusion, intraduodenal infusion of a solution containing only fat causes a modest increase in the number of reflux episodes in patients with reflux oesophagitis by increasing the percentage of transient LOS relaxations associated with reflux. Although interesting, these observations cannot be extrapolated to the physiological postprandial situation.

In the design of our study we were careful to avoid possible bias which may occur when testing different meals. Firstly, we chose a type of meal which allowed us to use the same volume and osmolarity on the two occasions. Gastric distension is a potent stimulus for transient LOS relaxation, ${ }^{7}$ and hyperosmolarity delays gastric emptying, ${ }^{8}$ which prolongs the time acid material is available for reflux in the oesophagus. Secondly, as a control meal we used a balanced meal with the energy content of carbohydrates, lipids, and proteins typical of the Italian diet. ${ }^{9}$ Thirdly, we administered part of the meal directly in the stomach in order to minimise the possibility that the subjects ate a different amount on the two days.

A lower LOS pressure has been observed in healthy subjects after a corn oil meal when compared with the fasting condition. ${ }^{10}$ This has been proposed as the possible cause of fatty food induced heartburn ${ }^{1}$; subsequently Becker et al have suggested that in patients with reflux disease gastro-oesophageal reflux may not increase after fat ingestion if they already have a low basal LOS pressure. ${ }^{2}$ Our study does not support this notion. We found similar LOS pressure after meals containing different amounts of fat and our high fat meal did not affect gastro-oesophageal reflux in any of the subjects studied, irrespective of the level of LOS pressure after the balanced meal.

In light of our results, should it be concluded that, despite clinical beliefs, fat does not increase gastro-oesphageal reflux in patients with reflux disease? We do not think so. Our study is not definitive and at least one other hypothesis remains to be tested with a longer observation period. Although the gastric emptying of the two meals may not differ because their volume and the energy density was the same, ${ }^{11}$ the possibility exists that a higher fat content delays gastric emptying $^{12}$ and consequently increases reflux in the late postprandial period by prolonging both gastric distension, which is a stimulus for transient LOS relaxation, ${ }^{7}$ and the presence of acid material in the stomach. Alternatively, fat reaching the small bowel could enhance perception of gastro-oesophageal reflux episodes without causing any increase in the acid load to the oesophagus. This possibility is supported by recent data showing that in dyspeptic patients intraduodenal lipid decreases the threshold gastric volume at which fullness is felt, suggesting that stimulation of duodenal chemoreceptors can influence sensation in other areas of the gut, possibly through neurohormonal mediation. ${ }^{13}$

Finally, a comment on the rate of transient LOS relaxations and their association with reflux. We found a significantly higher percentage of transient LOS relaxations accompanied by reflux in the patients, as have other authors, ${ }^{14}$ but only a trend towards a higher rate of transient LOS relaxations. The latter observation suggests that patients are heterogeneous in this respect, which may explain, at least in part, the conflicting findings in the literature. ${ }^{14}$

In summary, our study did not provide evidence for an increase in gastro-oesophageal reflux after fatty foods, at least for the first three postprandial hours, suggesting that the relationship between fat and induction of heartburn in reflux disease is more complex than commonly thought. This study was supported by a grant from the Associazione
Amici della Gastroenterologia del Padiglione Granelli.The work Amici della Gastroenterologia del Padiglione Granelli. The work was presented in part at the XV International Symposium on Gastrointestinal Motility, Rome 1995, and published in abstract
form (Neurogastroenterol Motil 1995;7:273).

1 Nebel O, Fornes M, Castell D. Symptomatic gastroesophageal reflux: incidence and precipitating factors. Dig Dis 1976;21:953-6.

2 Becker DJ, Sinclair J, Castell DO, Wu WC. A comparison of high and low fat meals on postprandial esophageal acid exposure. Am $\mathcal{F}$ Gastroenterol 1989;7:782-6. 
3 Schoeman $\mathrm{MN}$, Tippett MD, Akkermans LMA, et al. Mechanisms of gastroesophageal reflux in ambulant 5;108:83-91

4 Penagini R, Schoeman MN, Dent J, et al. Motor events underlying gastro-oesophageal reflux in ambulant patients
with reflux oesophagitis. Neurogastroenterol Motil 1996;8: 131-41.

5 Holloway RH, Penagini R, Ireland AC. Criteria for the objective definition of transient lower esophageal sphincter relaxation. Am f Physiol 1995;268:G128-33.

6 Holloway RH, Lyrenas E, Ireland A, et al. Effect of intraduodenal fat on lower oesophageal sphincter function and gastro-oesophageal reflux. Gut 1997;40:449-53.

7 Franzi S, Martin C, Cox M, et al. Response of canine lower esophageal sphincter to gastric distension. Am $\mathcal{F}$ Physiol 1990;259:G380-5.

8 Hunt JN, Pathak JD. The osmotic effects of some simple molecules and ions on gastric emptying. I Physiol molecules and ions
9 Ferro-Luzzi A, Spadoni MA, Turchetto E, et al. Livelli di assunzione giornalieri raccomandati di energia e nutrienti per la popolazione italiana a cura della Società Italiana di Nutrizione Umana. Milan: Litho Delta, 1989.

10 Nebel OT, Castell DO. Lower esophageal sphincter pressure changes after food ingestion. Gastroenterology 1972;63:77883.

11 Hunt JN, Stubbs DF. The volume and energy content of meals as determinants of gastric emptying. F Physiol 1975; 245:209-25.

12 Hunt JN, Knox MT. A relation between the chain length of fatty acids and the slowing of gastric emptying. F Physiol 1968;194:327-36

13 Barbera R, Feinle C, Read NW. Abnormal sensitivity to duodenal lipid infusion in patients with functional dyspepsia. Eur f Gastroenterol Hepatol 1995; 7:1051-7.

14 Mittal RK, Holloway RH, Penagini R, et al. Transient lower esophageal sphincter relaxation. Gastroenterology 1995;109: esophage 